\title{
Antônio Moniz de Souza, o 'Homem da Natureza Brasileira': ciência e plantas medicinais no início do século XIX*
}

\author{
Antônio Moniz de Souza, \\ the 'Man of Brazilian \\ Nature': science and \\ medicinal plants in the early \\ $19^{\text {th }}$ century
}

Laura Carvalho dos Santos

Mestre em história pela Universidade Federal da Bahia Av. D. João VI, 2/405

40285-001 - Salvador -BA - Brasil

poshistoria@yahoo.com.br

Submetido para publicação em maio de 2007.

Aprovado para publicação em novembro de 2008.
SANTOS, Laura Carvalho dos. Antônio Moniz de Souza, o 'Homem da Natureza Brasileira': ciência e plantas medicinais no início do século XIX. História, Ciências, Saúde - Manguinhos, Rio de Janeiro, v.15, n.4,

out.-dez. 2008, p.1025-1038.

Resumo

O início do século XIX, no Brasil, registrou intenso movimento de investigação da natureza e presença de várias expedições com o propósito de formar um corpo de conhecimentos sobre a flora brasileira. Tais expedições tinham como um de seus principais objetivos o mapeamento e a identificação de espécies vegetais que pudessem ser utilizadas para exploração econômica e em práticas terapêuticas.

Em tal contexto o viajante baiano Antônio Moniz de Souza viveu e desenvolveu suas atividades. Nas primeiras décadas do século XIX, percorreu algumas localidades do território brasileiro, observando, catalogando e coletando produtos dos três reinos da natureza. O estudo desse personagem põe em evidência características importantes da exploração da natureza e os saberes e usos de plantas medicinais no período.

Palavras-chave: viajantes; plantas medicinais; Antônio Moniz de Souza; século XIX; Bahia (Brasil).

\section{Abstract}

Early nineteenth century Brazil saw a vibrant movement to study nature, including a number of expeditions aimed at gathering a corpus of knowledge on Brazilian flora. One of the main goals of these expeditions was to map and identify plant species of economic and therapeutic value. The government undertook and sponsored various initiatives, and it was within this context that the Bahian voyager Antônio Moniz de Souza engaged in his activities. He traveled through areas of the Brazilian territory in the first decades of the nineteenth century, observing, cataloging, and collecting products from the three kingdoms, especially plants with medicinal powers. This study of Moniz de Souza pinpoints and analyzes important features in the exploration of nature and knowledge and the use of medicinal plants during this timeframe.

Keywords: science; travelers; medicinal plants; Antônio Moniz de Souza; Bahia. 


\begin{abstract}
Sem o reino vegetal nada existiria sobre a terra. Um campo sem plantas não tem beleza, chama-se esteril, e para nada presta! Todos os bens de que se goza são devidos ao reino vegetal, o mais rico dos reinos, e criador do animal. Por esta consideração cumpre que o viajante traga sempre nas algibeiras os germens dellas para quando achar terreno, e estação própria semear em proveito do paiz onde se achar, e do seu próprio.
\end{abstract}

Antônio Moniz de Souza (1843)

\begin{abstract}
$\mathrm{A}$ natureza brasileira, desde o início do período colonial, despertou o interesse da Coroa portuguesa e, posteriormente, da administração da nação já independente, em virtude da riqueza de seus reinos, profusos de produtos que poderiam ser utilizados para a exploração comercial e para as práticas de cura. Abundantes na flora, as plantas usadas para fins medicinais destacaram-se como importante conjunto de elementos utilizados para a cura dos males do corpo e do espírito. Os conhecimentos a seu respeito faziam parte de diferentes práticas culturais no Brasil, como as européias (Carneiro, 1994; Thomas, 1983), algumas trazidas ao Brasil por colonizadores portugueses; as africanas, trazidas com os escravos de diversas origens; e as indígenas (Ribeiro, 1997; Santos Filho, 1991; Soares, 2002). Juntas, essas práticas estabeleceram relações de forma extremamente dinâmica, preservando características e criando novas significações para os usos da flora.

Os remédios advindos da natureza foram amplamente empregados na cura das enfermidades que assolavam os habitantes das terras brasileiras, e os saberes sobre usos e propriedades das plantas medicinais foram, desde o século XVIII principalmente, estudados e divulgados no mundo científico, nos centros de botânica e história natural na Europa. Esse movimento também se fez presente no Brasil, que contribuiu para o estabelecimento e fortalecimento de uma rede de informações e circulação sobre as potencialidades e possíveis usos das drogas naturais.

As informações sobre a natureza brasileira foram produzidas a partir da aproximação e do estabelecimento de relações com os povos nativos, relatadas por viajantes, cronistas e religiosos. Como exemplos, citamos os relatos de Fernão Cardim (1978), dedicando capítulos a plantas medicinais; Gabriel Soares de Souza (1987), que descreveu as plantas da Bahia; e Pero Gandavo (1964), que deu notícia de algumas plantas medicinais. Essas informações continuaram a ser produzidas durante os séculos seguintes, e nas primeiras décadas do século XIX ocorreu a intensificação das ações oficiais para o mapeamento das riquezas naturais do Brasil e suas possíveis utilizações. Várias missões estrangeiras científicas vieram coletar dados sobre a natureza brasileira e estabeleceram-se instituições médicas oficiais no Brasil, com a realização de estudos, teorias e práticas, nos quais as plantas medicinais ocuparam importante espaço.

Já em fins do século XVIII a Europa vivenciou modificações no pensamento científico (Belluzo, 1994), e o movimento da Ilustração procurou dar à ciência um caráter utilitário, com o aproveitamento, pelo homem, dos elementos da natureza, incluindo as plantas usadas para fins terapêuticos. O projeto iluminista do Estado português procurou adotar ações que superassem o 'atraso' em relação a outras nações européias, no conhecimento de
\end{abstract}


suas riquezas naturais (Wegner, 2004, p.132). Lorelai Kury (2004) destaca que, naquele momento, o modelo imperial português deu lugar ao que chama de 'estratégias internacionais'. Anteriormente Portugal adotara uma política de não-divulgação a respeito dos produtos de suas colônias e não incentivava a aclimatação de espécies e estudos sobre cultivos e potenciais da flora. No período em questão, houve uma mudança de política, com ações de incentivo à aclimatação de espécies, trocas de informações sobre possíveis explorações econômicas e patrocínio de viagens cujo objetivo principal era mapear as riquezas naturais do Brasil.

Ângela Domingues (2001), por sua vez, mostra que a ciência luso-brasileira voltou-se para estudos que fornecessem informações sobre o Brasil, possibilitando ao Estado conhecer seus domínios e sobre eles ter maior controle. Buscou dessa forma um inventário sistemático das espécies nativas do Brasil, a maioria das quais era ainda desconhecida no período. Assim, as atividades desenvolvidas pelos viajantes, para obter conhecimentos sobre as riquezas naturais do Brasil, ganharam destaque. Foram construídas então redes de saberes e informações sobre a natureza brasileira (Kury, 2004), e no início do século XIX viajantes, medicina, história natural, o Estado, as instituições científicas e a flora brasileira estiveram em constante interação, em campos não imunes à política e às relações de poder.

No presente artigo, apresento o viajante baiano Antônio Moniz de Souza ${ }^{1}$, que nas primeiras décadas do século XIX percorreu diversas localidades do território brasileiro para observar, catalogar e coletar produtos da flora, entre os quais plantas medicinais estudadas e usadas por agentes da medicina acadêmica no período.

\section{A investigação da natureza no Brasil: início do século XIX}

Em 1801 a administração da capitania da Bahia recebeu do príncipe regente, através de d. Rodrigo de Souza Coutinho, instruções sobre o aumento do Real Jardim Botânico (Aviso..., 1801). A necessidade de expansão da botânica também foi mencionada por Coutinho, que pediu a colaboração dos administradores coloniais para a publicação de uma "Flora completa e Geral do Brasil, e de todos os vastos Dominios de Sua Alteza Real". Ressaltava que algum herborista ou jardineiro, conhecedor da natureza local, deveria formar uma coleção de sementes secas de todas as plantas da capitania, as quais seriam remetidas ao diretor do Jardim Botânico da Ajuda, em Portugal, com um catálogo sobre as mesmas. As instruções tratavam da conservação das amostras a serem enviadas: deveriam ser remetidas ainda conservadas e, quando possível, com a apresentação dos nomes pelos quais eram conhecidas nos locais onde haviam sido coletadas. Tais dados deveriam ser enviados anualmente.

Em 1812 d. João VI novamente promoveu ações de fomento das ciências naturais que, na perspectiva do 'espírito das Luzes', poderiam contribuir para o aperfeiçoamento da humanidade. A determinação régia estabelecia uma cadeira de história natural "em todas as capitais", enfatizando o ensino de conteúdos relacionados à botânica, zoologia, química e mineralogia. Uma Academia de Ciências Naturais também figurava no documento, e propunha-se que sábios viajassem por diferentes partes do Brasil e escrevessem sobre as possibilidades da natureza brasileira. Desse modo, uma brigada de engenheiros naturalistas 
exploraria "tantas preciosidades com que a Natureza eniqueceo estes vastissimos terrenos, rios e praias" (Determinação..., 1812).

Segundo Raminelli (2001), ocorreu de fato uma interiorização da ciência luso-brasileira, atuando os naturalistas como agentes imperiais e constituindo suas viagens valiosas fontes de informações sobre os três reinos da natureza nos locais percorridos. Para Lopes (1997, p.30), houve um "estatismo da produção científica", ou seja, iniciativas do Estado português redundaram em expedições de exploração cada vez menos militares e geopolíticas e mais 'filosóficas'. Representantes do Estado, como governadores, ouvidores e juízes, e ainda representantes da Igreja estiveram envolvidos nas remessas de materiais para o Real Museu, sendo eles analisados também pela Academia Real das Ciências.

No início do século XIX, a natureza brasileira continuou a ser objeto de várias expedições, sobretudo estrangeiras (Augel, 1975), favorecidas pelo contexto sociopolítico, principalmente pela abertura dos portos brasileiros. Para os propósitos deste artigo, merecem destaque as viagens de George Freyreiss, biólogo que veio ao Brasil em 1813 com o objetivo de formar coleções de história natural e passou pela Bahia; do príncipe Maximiliano de Wied-Nuwied; a Expedição Langsdorff; e principalmente a chamada Missão Austríaca (1817-1820), que percorreu várias regiões do Brasil, inclusive a Bahia, e teve as participações do médico e naturalista Carl von Martius e do zoólogo, naturalista e paleontólogo Johann von Spix. Foram observadas e catalogadas diversas espécies da fauna e da flora, e a obra dos cientistas representa importante fonte sobre a Bahia e sua farmacopéia, num período em que foi obtido o maior volume de informações sobre a natureza do país.

Foi em tal contexto que Antônio Moniz de Souza e Oliveira exerceu suas atividades de naturalista, sendo alcunhado por seus contemporâneos como o Homem da Natureza Brasileira (Souza, 2000).

\section{Antônio Moniz de Souza}

Na Bahia, no início do século XIX, havia intensa efervescência cultural e grande movimentação de estrangeiros envolvidos em expedições, atividades comerciais, agrícolas e industriais e prestação de serviços. Após a chegada da família real portuguesa ao Brasil, em 1808, houve uma aproximação com outras nações nos aspectos econômicos, político e cultural (Barreto, Aras, 2003). A capitania da Bahia representava um ponto estratégico na América portuguesa devido às suas ligações com a África e a Ásia. Era um porto de desembarque das naus que rumavam para o Oriente ou para o Reino e constituía também importante centro de difusão de espécies vegetais (Pataca, 2006). Salvador era a maior praça comercial da Bahia no início do século XIX, e importante centro comercial da América lusitana, mesmo tendo perdido parte de sua força econômica em virtude do desenvolvimento do centro-sul minerador e da mudança da capital para o Rio de Janeiro (Junqueira, 2005).

Sobre as riquezas naturais da capitania, o jornal Idade D'Ouro noticiava, em 20 de agosto de 1811:

Parece que a mesma Natureza agradecida se esmera em revelar nesta épocha feliz algumas das suas proveitosas raridades. Descobrio-se na Villa da Cachoeira ... huma fonte de água férrea 
de tão superior qualidade, que os experimentados Naturalistas, e Botânicos pasmarão ao ver a força, com que em menos de dous minutos produziu os mesmos effeitos, que elles esperavão, segundo as regras da Faculdade, não se pode executar em menos de cinco. ... Parece este hum objecto digno de que os senhores iniciados, ou Professores de taes estudos se dignem a ir em obsequio do publico examinar, e experimentar tão recomendável preciosidade.

O príncipe regente recorreu ao conde dos Arcos, considerado importante promotor do desenvolvimento da ciência no Brasil, para a criação, na cidade da Bahia, de um curso de agricultura através de carta régia datada de 25 de junho de 1812 (carta régia, 25 jun. 1812). Um ano depois, em 28 de julho de 1813, foi pedida uma declaração acerca dos produtos medicinais indígenas de cada capitania e ordenou-se aos governadores que consultassem o físico-mor sobre a qualidade e quantidade dos produtos e o modo mais adequado de os enfermos do Hospital Real Militar da Corte usarem-nos. Pediu-se ainda que fossem indicados os custos da extração daqueles produtos por conta da própria Real Fazenda e de pessoas que traficavam tais mercadorias (Decisões, 1813). A declaração do físico-mor deveria ser enviada ao regente, junto com observações que os governadores julgassem oportunas, através da Secretaria do Estado dos Negócios Estrangeiros e da Guerra.

No período em questão, a medicina foi influenciada pela busca das propriedades e potencialidades econômicas e terapêuticas da flora brasileira, participando das descobertas obti-das pelas expedições científicas e utilizando largamente as plantas medicinais. Lycurgo Santos Filho (1991) considera que as viagens ao interior, empreendidas por portugueses e brasileiros por ordem dos governos colonial e imperial, omitiram por completo, com raras exceções, observações de natureza médica, as quais, em contrapartida, são abundantes nos relatos dos viajantes estrangeiros. Para o autor, estes trazem, junto com as observações sobre clima e costumes, descrições sobre hospitais, epidemias, praticantes de cura, medicinas indígena e popular, vegetais utilizados no tratamento de doenças, entre outros aspectos relevantes para a história da medicina.

Assim, visando preencher uma lacuna da historiografia acerca de viajantes nacionais que tenham feito observações relacionando a natureza brasileira e as práticas de cura, analiso a trajetória e as atividades desenvolvidas pelo brasileiro Antônio Moniz de Souza. Consta que ele nasceu no ano de 1782, numa família de agricultores, às margens do rio Real de Nossa Senhora de Campos, termo da vila de Lagarto, então pertencente à província da Bahia (em 1823 a vila passou a fazer parte da província de Sergipe). Até 1807 Moniz de Souza viveu em Lagarto como vaqueiro, comerciante e militar, e lutou contra bandos armados que atuavam no sertão.

Em algumas fontes Moniz de Souza é citado como capitão de ordenanças. Os Corpos de Ordenanças foram estabelecidos no Regimento das Ordenanças e dos Capitães-Mores, de 1570, que determinava que fosse organizada toda a população adulta masculina entre os 18 e sessenta anos, capaz de combater, sabendo-se que ninguém nessas condições poderia, a partir de então, eximir-se do serviço militar não remunerado. $\mathrm{O}$ alistamento ao serviço militar gratuito estendia-se a todos os lugares, fossem aldeias, vilas ou cidades (Mello, 2006). Os recrutados eram conhecidos também como 'paisanos armados', ou seja, homens sem instrução militar sistemática que eram organizados em terços, por sua vez subdivididos em companhias, e utilizados em missões de caráter militar e em atividades de controle 
interno. Os postos de ordenanças de mais alta patente eram capitão-mor, sargento-mor e capitão (Costa, jan. 2007). Vale lembrar que, no início do século XIX, o governo baiano enfrentou dificuldades para manter a ordem pública, havendo constantes revoltas e insubordinações militares, crise no abastecimento alimentar de Salvador, revoltas escravas e contestação da ordem pública nos sertões (Junqueira, 2005).

Moniz de Souza possuía patente de capitão e como tal liderou investidas contra bandos de 'facinorosos'. Em 1807, sem formação acadêmica, partiu de sua terra natal com intenção de ir para Portugal combater as tropas napoleônicas, mas naufragou em Pernambuco e, ferido, foi transportado para o Rio de Janeiro, onde ingressou como noviço no Convento de Santo Antônio. Ali, com frei José Mariano da Conceição Velloso, teve lições de botânica e participou de excursões para observar e catalogar plantas com possíveis propriedades terapêuticas.

A relação estabelecida com frei Velloso foi, ao que tudo indica, a base dos conhecimentos sobre viagens de exploração da natureza que, depois, Moniz de Souza desempenharia de forma sistemática. Frei Velloso tivera formação autodidata de naturalista em paralelo à formação religiosa. No Brasil, inserido na sociedade letrada da época, principalmente entre 1779 e 1790, Velloso enviara espécies vegetais ao Museu da Ajuda e fora responsável por um amplo levantamento da flora fluminense, a pedido do governo português. Entre 1799 e 1801 estivera à frente da Casa Literária do Arco do Cego, em Lisboa, tendo sido responsável pela publicação de várias obras sobre agricultura, navegação e medicina, entre outros assuntos (Wegner, 2004). Após essa estada em Portugal, retornou ao Brasil em 1808.

Apesar de permanecer no Convento por algum tempo, Moniz de Souza não quis seguir a vida religiosa e optou por tornar-se herborista. Iniciou então suas atividades de viajante e explorador da natureza brasileira, em que se destacou na busca de plantas medicinais. Em 1812 regressou à Bahia e começou a aplicar seus conhecimentos para conseguir dinheiro. No Recôncavo Baiano colhia plantas medicinais e as fornecia a médicos, farmacêuticos e boticários. Moniz de Souza (2000, p.43) escreveu, sobre esse período:

\footnotetext{
Assim para fazer observações sobre produtos da natureza ... como colher alguma Ipicacoanha para vender, com o lucro do qual ... me ia suprindo modicamente, e de todas as vezes que voltava à cidade tinha a Glória de apresentar o meu trabalho botânico aos médicos, e farmacêuticos, a quem com gosto eu ofertava algumas das minhas produções, pelo que fui ganhando alguns conhecimentos e amizades ...
}

Na Bahia, Souza estabeleceu contato com diversas pessoas e teve como patrocinadores de suas viagens homens ilustres da sociedade local, principalmente gente ligada à profissão médica e ao Colégio Médico-Cirúrgico. ${ }^{2}$ Contou também com o apoio dos governadores da província, conde dos Arcos e conde de Palma, que chegaram a promover subscrições para que ele realizasse suas viagens. Médicos citados em seus relatos pertenciam ao Hospital Real Militar, como Antônio Ferreira França e João Ramos de Araújo e ainda José Lino Coutinho (Burns, maio-dez. 1969).

O trabalho de Moniz de Souza foi reconhecido pela elite local como o de um 'botânico'. Em 1817 partiu em viagem pelo sertão baiano, passando por Cachoeira, Camisão, Orobó e Jacuípe. Retornou à capital da província e apresentou ao conde dos Arcos os gêneros vegetais que recolheu. Estes foram submetidos ao exame do doutor Sebastião Navarro de 
Andrade, professor da cadeira de química teórica e aplicada a "diferentes artes e ramos da industria", criada em 1817 no Colégio Médico-Cirúrgico. Dias depois, o conde chamou Moniz de Souza e, como prova da satisfação com o trabalho que vinha fazendo, ofereceulhe a sua proteção para que fosse à Europa estudar a história natural e fazer observações por lá (Souza, 2000, p.43-44).

O viajante não foi à Europa, mas animado com a importância de seu trabalho para a prática da medicina no país, partiu, em 1818, para a região que viria a ser a província de Sergipe e ali fez copiosas coletas e observações. No período vigorava o governo do conde de Palma, que confirmou a licença dada pelo antecessor para a realização das viagens. Vale destacar que, desde 1820, passou a ser exigido passaporte das pessoas que entravam e saíam do Brasil. Em nome da segurança, conservação da ordem pública e tranqüilidade do Reino, foi ordenado: "Nenhuma pessoa, seja nacional ou estrangeira, de qualquer classe ou condição que for, se permitirá que desembarque e possa entrar em parte alguma deste reino do Brazil, sem que venha munida e apresente o seu competente passaporte ou portaria, que verifique a sua qualidade, logar donde sahiu, e destino a que se dirige." Em outra passagem determinava-se que, de $1^{\circ}$ de junho de $1821 \mathrm{em}$ diante, toda pessoa que viesse do exterior para o Reino deveria trazer "passaporte do meu Embaixador, Ministro ou Encarregado de Negócios, residente no paiz, donde ella vier, alem do passaporte da competente autoridade que permitta a sua sahida" (Decreto, 2 dez. 1820).

Ao voltar da excursão a Sergipe, em 1819, Souza mostrou os vegetais coletados ao governador e a professores e médicos, como José Lino Coutinho, Sebastião Navarro de Andrade, João Ramos, Antônio Ferreira França e Silveira Lopes, como também a cirurgiões e farmacêuticos da Bahia (Souza, 2000, p.45).

Em 1820 viajou para o Norte, mas a Guerra de Independência na Bahia, em 1823, impediuo de alcançar seu objetivo, e ele só chegou até o interior de Pernambuco. Em 1824 iniciou nova viagem rumo ao Rio de Janeiro, onde chegou em 1828, passando antes por Campos dos Goytacases. Moniz de Souza conta que foi bem recebido na corte por membros da elite imperial, que deram tanta importância a seu trabalho que lá foi cognominado o Homem da Natureza e ainda o Filósofo da Natureza Brasileira. Além disso, a Câmara do Rio de Janeiro promoveu subscrição para impressão de suas descobertas (Souza, 2000, p.49-50).

Nessa viagem em direção à Corte, Souza chegou à vila de Porto Seguro em abril de 1825, onde pôde ajudar a população na luta contra uma peste não especificada pelo viajante, com os medicamentos que levava consigo. Ali indagou sobre os reinos animal, vegetal e mineral e, pelo rio Jequitinhonha, navegou até Minas Novas, em Minas Gerais, onde descobriu pedras preciosas de várias qualidades e ouro (Requerimentos..., s.d.).

Nos anos em que se deslocou por diferentes partes do Brasil, Souza interagiu com agentes da administração colonial e, a partir de 1822, imperial, e travou contato com comunidades sertanejas e indígenas. Suas atividades foram reguladas e controladas pelo governo num período em que as descobertas de riquezas e suas aplicações constituíam uma 'questão de Estado'. Precisava de constantes autorizações para deslocar-se e realizar suas atividades. Em 1825 encontramos o capitão das ordenanças da vila do Lagarto no distrito de Minas Novas, apresentando-se como descobridor de produtos importantes para a nação. Portava documentos que comprovavam suas atividades e requeria permissão para executar seu 
trabalho no distrito sem obstáculos. Informava até que suas descobertas haviam sido apresentadas ao imperador (Requerimentos..., s.d.). Ao regressar de Minas Novas, onde fez descobertas que considerou úteis ao Estado e à nação, Souza solicitou, na vila de Porto Seguro, que os produtos por ele coletados fossem guardados com toda segurança nas Câmaras das Comarcas, até que fossem transportados até o Rio de Janeiro, para ser entregues ao imperador. Efetivamente, em abril de 1826 ordenou-se que as referidas Câmaras prestassem ao capitão todo auxílio possível a bem do progresso nacional, sem, contudo, onerar os cofres públicos (Requerimentos..., s.d.).

Muitas regiões percorridas por Moniz de Souza possuíam grande variedade de produtos vegetais considerados úteis à medicina, como raízes, cascas, óleos, resinas, gomas e essências. Havia também, a explorar, ouro e pedras preciosas, que alcançavam elevados preços nos mercados do Rio de Janeiro e da Europa. Também tinham valor comercial animais capturados na floresta como onças, lontras, gatos-do-mato, antas, veados e preguiças. Em muitos dos territórios por ele percorridos viviam os denominados Botocudos, povos que entraram em contato com expedições que passaram na região. Destaque-se que, no período das viagens de Moniz, vivia-se um processo de combate aos Botocudos, iniciado pelo príncipe d. João em princípios do século XIX. Justificou-se a declaração de guerra com base no argumento de que os índios eram antropófagos. Outro fator a ser assinalado é a crise na mineração, que teria levado um movimento de colonização para outras terras, fosse para plantar ou procurar áreas mineradoras. Os índios ocupavam uma área importante desse território e as margens do rio Doce, importante via navegável para se alcançar o Espírito Santo. A conjugação desses fatores explicaria a decisão de combatê-los. A guerra durou muitos anos e só foi oficialmente revogada pelo governo regencial em 1831, mas os combates mais violentos se deram entre 1808 e 1824. Esses povos da região eram os antigos Aimorés ou Crens (Guerens), que, empurrados pela expansão dos colonos, se deslocaram do Norte para o Sul, passando a ser conhecidos pela designação Botocudos. No século XIX havia lutas e animosidades contra os Botocudos, mas também ocorreu o estabelecimento de relações amistosas com alguns de seus grupos, na época da presença constante de naturalistas estrangeiros na área. Houve também interlocuções com viajantes nacionais, inseridos no contexto de políticas de governo voltadas para a exploração da flora e, ao mesmo tempo, para o controle dos povos indígenas.

Souza parece ter realizado suas viagens com número variável de acompanhantes. Há documentos que registram viagens apenas com um, José Marcelino da Silva, que serviu como interlocutor para a aproximação com os povos indígenas. Outras viagens contaram com a presença de várias pessoas, ao que parece organizadas rigidamente e com aval oficial. Já no período imperial, uma portaria de abril de 1827 da vila de Alcobaça autorizava Francisco Muniz Cordeiro a comandar 21 homens na entrada que Souza faria para descobrir riquezas dos reinos animal, vegetal e mineral. Ele havia solicitado tal auxílio ao ouvidor interino, para melhor controlar os homens que o acompanhariam e que teriam, entre outras incumbências, a de tratar com o "gentio bárbaro", o qual, se possível, seria conduzido para aquela vila a fim de ser batizado na "religião católica romana" e viver sob as "leis do Império" (Requerimentos..., s.d.). Infelizmente o documento não traz informações sobre os participantes, como idade, função, atividades realizadas, mas ainda assim nos permite 
supor que essa expedição foi de grande porte. O interesse do Estado pelas atividades daquele explorador da natureza revela-se na sugestão de que houvesse "cuidado" no decorrer dos contatos e aproximações com o "gentio" para que seus componentes "amansassem" (Requerimentos..., s.d.). Segundo as instruções oficiais, os índios capturados em combate poderiam ser escravizados por dez anos, período passível de prorrogação por mais dez anos. Tal prática foi mantida até a década de 1840, quando autoridades locais começaram a posicionar-se contra a escravização indígena e forçaram os proprietários a libertar os índios que haviam sido pegos ainda na época de d. João VI.

Notam-se semelhanças entre as viagens de Souza e as de frei Velloso, que, como vimos, deu àquele as primeiras noções de botânica e influenciou sua maneira de buscar as riquezas naturais. Sabemos que frei Velloso trabalhou como missionário junto aos indígenas e colecionou plantas raras e outros materiais de importância para a história natural, a pedido do governador de São Paulo, Martim Lopes Lobo de Saldanha. As principais funções de frei Veloso relacionavam-se a atividades missionárias de conversão de indígenas ao cristianismo e à administração de algumas aldeias sob a jurisdição da Ordem dos Franciscanos em São Paulo. Essas atividades foram realizadas, também, durante a expedição botânica no Rio de Janeiro, que culminou com a publicação da obra Flora fluminensis (Velloso, 1961). Assim, as atividades de Velloso tinham uma singularidade em relação a outras viagens filosóficas, pois além do levantamento científico tinham uma função missionária, que, aliás, envolvia a participação de mais três religiosos (Pataca, 2006).

Em julho de 1827 Souza esteve na vila de Caravelas, de onde pretendia seguir para o Rio de Janeiro a fim de apresentar à corte o resultado de seus descobrimentos. Para tanto requereu o auxílio "dos animos desejosos do melhoramento e prosperidade desta Provincia, e de todo o Imperio Brasileiro, em cuja utilidade se redunda o seu trabalho; por isso supplica-se se dignem ajudalo por intermedio de huã subscrição". De fato, Moniz de Souza obteve essa subscrição: em agosto do mesmo ano ordenou-se às Câmaras da comarca que fosse apresentada a atestação de suas viagens e do valor de seu trabalho, e ainda que the prestassem todas as 'ajudas' de que viesse a necessitar, ressaltando-se, porém, mais uma vez, que não deveriam onerar os cofres nacionais (Requerimentos..., s.d.). E em 1828 pedia-se que não se pusesse "empedimento algum ao livre transito de Antonio Munis de Souza que vai desta $\mathrm{V}^{\mathrm{a}}$ [viagem] por terra à Corte do Rio de Janeiro levando em sua companhia Jose Marcelino da Silveira" (Requerimentos..., s.d.).

Não conseguimos identificar precisamente os setores ou integrantes da elite imperial com quem Moniz de Souza estabeleceu relações após sua chegada à Corte e que possivelmente intercederam a favor da publicação das obras do viajante, até hoje por nós conhecidas. Sabe-se que os exemplares que coletara durante três décadas de trabalho foram oferecidos ao Museu Nacional, e que os resultados de seus estudos vieram a lume em Viagens e observações de um brasileiro que desejando ser útil à sua pátria se dedicou a estudar os usos e costumes de seus patrícios, e os três reinos da natureza, em vários lugares e sertões do Brasil, oferecidos á nação brasileira, planejada originalmente em dois tomos. Em 1834 publicou-se, no Rio de Janeiro, o primeiro deles, com relatos de suas viagens pelos sertões da Bahia e do Rio de Janeiro, nos quais se dá grande ênfase à sociedade do interior e à importância da agricultura e dos pequenos lavradores como base da nação. ${ }^{3}$ Esse tomo foi escrito com forte espírito de 
crítica social, denunciando o autor, entre outras coisas, o banditismo, a opressão contra as mulheres, as arbitrariedades nas práticas militares, a corrupção dos juízes, a ociosidade da elite, a falta de cuidados com os animais e a terra, e a falta de atenção das autoridades com os pequenos agricultores do interior do Brasil.

O segundo tomo da obra de Moniz de Souza denomina-se Descobertas curiosas, que nos reinos vegetal, animal e mineral, por sítios e sertões de brasílicas províncias: Bahia, Sergipe e Alagoas fez o capitão Antônio Moniz de Souza e Oliveira, natural da primeira, com uma breve descrição primordial do lugar do nascimento e princípios de sua educação. A obra é oferecida "ao Augusto Chefe da Nação brasileira, o Sr. D. Pedro Primeiro, Imperador e Defensor Perpétuo do Brasil". Publicado antes do primeiro tomo, em 1824, apresenta "um repertório de utilidade de vários produtos da natureza, escrito em homenagem a Pedro I" (Pádua, 2002, p.189). Esse tomo pode ser considerado uma importante contribuição para a medicina, pois "foram 193 espécies catalogadas ... e mais da metade delas era desconhecida pelos pesquisadores em 1854, quando foi publicado o Sistema de Matéria Médica Vegetal, de Martius e Spix" (Nascimento, 2005, p.17). Constam dele também um catálogo de ervas, resinas, drogas, plantas e raízes, com seus usos terapêuticos, relatos sobre a infância do autor e suas impressões sobre os povos que estabeleceu contatos, em especial os indígenas.

O jornal O Censor Brasileiro, em sua edição de 24 de junho de 1828, exaltou as atividades realizadas por Souza:

as grandes potências européias gastavam grandes somas em expedições científicas para a exploração das riquezas do Brasil, como as Langsdorff, Saint Hilaire, Spix, Martius e outros. Eis que surgira um brasileiro, acrescentam os editores do jornal, que com subscrições insignificantes e sem estudos realizara trabalhos tão importantes quanto os dos estrangeiros. Após doze anos em viagens nas províncias de Pernambuco, Alagoas, Sergipe e Bahia, trazia à Corte conhecimentos sobre as propriedades de vegetais até então conhecidas somente dos caboclos do interior do país (citado em Souza, 2000).

Ilka Leite (1996) ressalta que os viajantes do início do século XIX organizaram os dados coletados em suas viagens por métodos científicos e com objetivos políticos e econômicos. Os naturalistas estavam vinculados tanto aos governos dos seus países de origem, que muitas vezes os financiavam, como aos representantes do governo do Brasil, primeiro coloniais, depois imperiais. Nesse mesmo contexto, Antônio Moniz de Souza também estabeleceu relações com governantes e autoridades. Em 1825, após a viagem pelo rio Jequitinhonha, enviou pelo menos 64 exemplares de produtos naturais para a Corte. Teriam sido entregues a várias repartições, mas só chegaram ao Museu Nacional em 1829. Encaixotados por quatro anos, "sobraram apenas alguns produtos botânicos e algumas pedras, tendo sido perdida a maioria dos produtos devido ao caruncho que reduziu tudo a pó e às baratas" (Lopes, 1997).

\section{Considerações finais}

Antônio Moniz de Souza apresentava-se como um patriota interessado no destino do país, e suas reflexões parecem seguir a linha de outros teóricos do período. José Augusto Pádua (2002) analisou a discussão ambiental e as idéias sobre o destino do Brasil nos 
séculos XVIII e XIX, com base em 150 textos de cinqüenta autores, entre eles Moniz de Souza. Evidenciou a importância da natureza e de seus produtos na construção da identidade do Brasil no período. Para ele, esse tipo de pensamento estava profundamente enraizado no ideário iluminista herdado do século XVIII, quando meio ambiente e recursos naturais constituíam fontes de progresso e entendia-se que estes deveriam ser utilizados de forma racional e cuidadosa, devido a seu potencial econômico. Assim, a natureza era vista como um objeto político, um recurso essencial para o avanço social e econômico do país. Não obstante, para Pádua, Moniz de Souza, embora tenha sido um autor "dotado de biografia tão inusitada, apartado da formação intelectual da elite, acabou por apresentar elementos semelhantes aos que demarcaram o ideário básico daquela tradição intelectual" (p.193-194).

O pesquisador Jorge Nascimento (2005), ao estudar as primeiras manifestações de pesquisa científica em Sergipe, refere-se a Antônio Moniz de Souza como um naturalista brasileiro pioneiro que, em 1818, percorreu a região para estudar espécies vegetais. Influenciado pelo frei José Mariano da Conceição Velloso, Moniz de Souza teria adotado o modo de fazer ciência próprio do mundo ocidental durante a primeira metade do século XIX. O autor ressalta, ainda, que a maior parte da bibliografia sobre o assunto produzida no Brasil prioriza o período republicano, deixando de lado o debate havido durante o século XIX em todo o país e, particularmente, na região Nordeste. (p.8).

Raquel Fonseca (1999) afirma que os cientistas do período, como grupo social, compreenderam que o conhecimento científico era um poderoso instrumento para o desenvolvimento da sociedade, influenciados que estavam pelas idéias iluministas, tais como a de utilidade da ciência, racionalismo, ecletismo e uso de procedimentos experimentais. A saúde e sua promoção, por sua vez, foram compreendidas como conhecimentos indiscutivelmente úteis e mereceram a atenção dos ilustrados. Assim, a prática dos cientistas nacionais afirmaria "a plena capacidade dos brasileiros de pensar, produzir e gerar recursos para seu próprio benefício" (p.100).

Personagem importante para entendermos a constituição da ciência no Brasil, a Ilustração luso-brasileira e baiana e os usos de plantas medicinais na medicina, Antônio Moniz de Souza desempenhou o papel de observador da natureza e deixou registros relevantes num contexto em que se valorizavam, sobretudo, a presença de naturalistas estrangeiros e o grande interesse de suas nações de origem por seus trabalhos.

As fontes consultadas permitem seguir ainda por alguns anos os passos do viajante, após a chegada ao Rio de Janeiro. Em 11 de julho de 1829, foi prorrogada por mais seis meses a licença a ele concedida, "a fim de viajar por todo o Imperio para continuar nos trabalhos de suas indagações sobre os productos dos tres Reinos da Natureza. E manda que todas as Authoridades a quem elle apresentar os ditos productos, os recebão, e remetam à Secretaria de Estado dos Negocios do Imperio, para passarem ao Museu Imperial e Nacional desta Corte" (Requerimentos..., s.d.).

Outro documento, de 31 de julho de 1841, afirma que "Antônio Muniz de Souza, cidadão brasileiro, realizara durante quarenta anos trabalhos e sacrifícios feitos a bem do país e da humanidade, para descobrir e colher as inúmeras riquezas naturais, obtendo como resultado mais de trezentas espécies de plantas, das quais propagou pelo seu país e forneceu quantidades aos estrangeiros curiosos, incluindo um grande número de 
medicinais, cujas virtudes haviam sido verificadas pelos médicos e botânicos mais abalizados do Império" (Requerimentos..., s.d.).

Moniz teria formado várias coleções com produtos dos três reinos da natureza, fornecendo-as aos capitães-generais da Bahia e de Sergipe, ao presidente da Junta Provisória das Alagoas, ao Museu Imperial, Jardim Botânico, entre outras instituições. O próprio Moniz salientou que fizera chegar os frutos de seus esforços a muitas nações do Novo e do Velho Mundos, onde existiam museus ricos em produtos por ele colhidos, a exemplo de Brasil, Estados Unidos, França, Grã-Bretanha, Portugal, Alemanha (Requerimentos..., s.d.).

Vemos que ele prosseguiu em sua carreira até pelo menos a década de 1840, uma vez que, para encerrá-la, solicitou em 1841 o privilégio de exploração de minas na comarca de Porto Seguro, na província da Bahia (Requerimentos..., s.d.). Moniz de Souza casou-se com Maria Firmina de Abreu Rangel, em 1840, e viveu em Niterói até seu falecimento, em 1857. Uma obra sua, de 1843, Máximas e pensamentos praticados por Antônio Moniz de Souza, foi por ele apresentada como sua despedida dos numerosos amigos e benfeitores que o tinham acompanhado na longa jornada pelos caminhos da natureza brasileira. ${ }^{4}$

\section{NOTAS}

* As informações e discussões deste artigo fazem parte da minha dissertação de mestrado, apresentada à Universidade Federal da Bahia (Santos, 2008).

${ }^{1}$ Alguns documentos adotam a grafia Antônio Muniz de Souza; outros adotam também os sobrenomes Souza e Oliveira. Optei pela grafia Antônio Moniz de Souza por ser ela a mais freqüente na documentação.

${ }^{2}$ Por carta régia de 19 de dezembro de 1815, a Escola de Cirurgia, fundada em 1808 na Bahia, teve ampliado o seu curso, que foi transferido para o Hospital da Misericórdia de Salvador, em 1816. A instituição passou, então, a se chamar Academia Médico-Cirúrgica da Bahia ou Colégio Médico-Cirúrgico.

${ }^{3}$ No final desse volume há um anexo intitulado "Breve notícia sobre a revolução do Brasil, por serem estes lugares os que tenho viajado desde a época da constituição, sobre o que descrevo o que tenho observado e ouvido dizer, etc.".

${ }^{4}$ Outros escritos de Antônio Moniz levantados são: Máximas e pensamentos praticados por Antônio Moniz de Souza, o 'homem da natureza' em suas viagens pelos sertões do Brasil desde 1812 até 1840. Publicados por um amigo, Niterói, 1843, em que apresenta regras de conduta para viajantes e cidadãos e preconiza a importância da conservação da flora e das matas para as gerações seguintes, assim como o reconhecimento da utilidade das plantas, dever não só dos viajantes; "Petição dirigida a SMI", publicado no Jornal Philantropo, no Rio de Janeiro em 1850, e "Tratamento da Morféia pela casca da raiz de Sucupira", publicado no Correio Sergipense em 8 de agosto de 1855.

\section{REFERÊNCIAS}

AUGEL, Moema Parente.

Visitantes estrangeiros na Bahia oitocentista. Dissertação (Mestrado) - Universidade Federal da Bahia, Salvador. 1975.

AVISO...

Aviso dirigido aos governadores interinos da Bahia, participando ordem do príncipe regente de que seja enviada uma coleção de sementes de todas as plantas da capitania, para que se possa publicar uma flora completa e geral do
Brasil. I-31, 30, 105. (Fundação Biblioteca Nacional - FBN). 1801.

BARRETO, Maria Renilda; ARAS, Lina Maria B. de. Salvador, cidade do mundo: da Alemanha para a Bahia. História, Ciências, Saúde Manguinhos, Rio de Janeiro, v.10, n.1. 2003.

BELLUZZO, Ana Maria.

O Brasil dos viajantes,v.2: Um lugar no universo. São Paulo: Fundação Odebrecht. 1994. 
BURNS, E. Brandford.

José Lino Coutinho e a Academia das Ciências: novos dados para a sua biografia. Universitas, Salvador, n.34, sep. maio-dez. 1969.

CARDIM, Fernão.

Do clima e terra do Brasil e algumas coisas notáveis que se acham assim na terra como no mar. São Paulo: MEC. 1978.

CARNEIRO, Henrique.

Filtros, mezinhas e triacas. São Paulo: Xamã. 1994.

CARTA RÉGIA.

In: Código Brasiliense, 1811-1822. Rio de Janeiro: Imprensa Régia, [1822]. 25 jun. 1812.

COSTA, Ana Paula Pereira.

Trajetórias e carreiras militares no contexto do Império português: promoções e conflitos nos atos eleitorais para postos dos Corpos de Ordenanças, comarca de Vila Rica, 1735-1777. Revista Espaço Acadêmico, n.68. Disponível em: http://www.espacoacademico.com.br/068/ 68costa.htm. jan. 2007.

\section{DECISÕES.}

In: Código Brasiliense, 1811-1822. Rio de Janeiro: Imprensa Régia, [1822]. 1813.

\section{DECRETO.}

In: Código Brasiliense, 1811-1822. Rio de Janeiro: Imprensa Régia [1822]. 2 dez. 1820.

\section{DETERMINAÇÃO...}

Determinação régia criando em todas as capitais uma cadeira de história natural e, no Rio de Janeiro, o curso de filosofia, o Colégio Geral de Medicina e a Academia de Ciências Naturais. II-30,33,006 n.001. (FBN). 1812.

DOMINGUES, Ângela.

Para um melhor conhecimento dos domínios coloniais: a constituição de redes de informação no Império português em finais do Setecentos. História, Ciências, Saúde -

Manguinhos, Rio de Janeiro, v.8, supl., p.823-838. 2001.

GANDAVO, Pero.

História da província de Santa Cruz. São Paulo: Obelisco. (Cadernos de História). 1964.

FIGUEIRÔA, Sílvia F. de M.; SILVA, Clarete Paranhos da; PATACA, Ermelinda Moutinho. Aspectos mineralógicos das 'viagens filosóficas' pelo território brasileiro na transição do século XVIII para o século XIX. História, Ciências, Saúde - Manguinhos, Rio de Janeiro, v.11, n.3, p.713-729. set-dez. 2004.

FONSECA, Maria Rachel Fróes da. Luzes da ciência na corte americana: observações sobre o periódico O Patriota. Anais do Museu Histórico Nacional, Rio de Janeiro, v.31, p.81-104. 1999.

JUNQUEIRA, Lucas de Faria.

A Bahia e o Prata no Primeiro Reinado: comércio, recrutamento e guerra cisplatina. Dissertação (Mestrado em História) - Universidade Federal da Bahia, Salvador. 2005.

KURY, Lorelay.

Homens de ciência no Brasil: impérios coloniais e circulação de informações (1780-1810.). História, Ciências, Saúde - Manguinhos, Rio de Janeiro, v.11, supl. 1, p.109-129. 2004.

LEITE, Ilka B.

Antropologia da viagem: escravos e libertos em Minas Gerais no século XIX. Belo Horizonte: Editora UFMG. 1996.

LOPES, Maria Margaret.

O Brasil descobre a pesquisa científica: os museus e as ciências naturais no século XIX. São Paulo: Hucitec. 1997.

MELLO, Cristiane Figueiredo Pagano de. Os Corpos de Ordenanças e Auxiliares: sobre as relações militares e políticas na América portuguesa. Revista História: Questões \& Debates, Curitiba, n.45, p.29-56. 2006.

NASCIMENTO, Jorge Carvalho do. Anotações sobre a botânica em Sergipe durante a primeira metade do século XIX. Revista da Fapese, Aracaju, v.1, n.1, p.7-22. 2005.

PÁDUA, José Augusto.

Um sopro de destruição: pensamento político e crítica ambiental no Brasil escravista (1786-1888). Rio de Janeiro: Jorge Zahar. 2002.

PATACA, Ermelinda Moutinho.

Terra, água e ar nas viagens científicas portuguesas (1755-1808). Tese (Doutorado em Geociências) - Universidade Estadual de Campinas, Campinas. 2006.

RAMINELLI, Ronald.

Do conhecimento físico e moral dos povos: iconografia e taxionomia na Viagem Filosófica de Alexandre Rodrigues Ferreira. História, Ciências, Saúde - Manguinhos, Rio de Janeiro, v.8, supl., p.969-992. 2001.

\section{REQUERIMENTOS...}

Antônio Muniz de Souza. Requerimentos encaminhados ao Ministério do Império. (20 documentos). C-0008, 025. (FBN). s.d.

RIBEIRO, Márcia Moisés.

A Ciência dos Trópicos: a arte médica no Brasil do século XVIII. São Paulo: Hucitec. 1997.

SANTOS FILHO, Lycurgo.

História geral da medicina no Brasil. São Paulo: Hucitec. 1991. 
SANTOS, Laura Carvalho dos.

Homens e natureza: saberes e usos de plantas medicinais a partir dos relatos do viajante Antônio Moniz de Souza. Salvador (18081828). Dissertação (Mestrado em História) Universidade Federal da Bahia, Salvador. 2008.

SOARES, Márcio de Souza.

Cirurgióes negros: saberes africanos sobre o corpo e as doenças nas ruas do Rio de Janeiro durante a primeira metade do século XIX. Revista Locus, Juiz de Fora, v.8, n.2. 2002.

SOUZA, Antônio Moniz de.

Viagens e observações de um brasileiro. Salvador: Instituto Geográfico e Histórico da Bahia. 2000.

SOUZA, Antônio Moniz. de.

Máximas e pensamentos praticados por Antônio Moniz de Souza, o "homem da natureza" em suas viagens pelos sertões do Brasil desde 1812 até 1840 - publicados por um amigo. Niterói: s.n. 1843.

SOUZA, Gabriel Soares de.

Notícias do Brasil, descrição verdadeira da costa daquele estado, que pertence à Coroa do reino de Portugal, sítio da Bahia de Todos os Santos. São Paulo: Nacional. 1987.

THOMAS, Keith.

O homem e o mundo natural. São Paulo: Companhia das Letras. 1983.

VELloso, José Mariano da Conceição. Flora fluminensis. Rio de Janeiro: Arquivo Nacional. (Publicações Históricas, 48). 1961.

WEGNER, Robert.

Livros do Arco do cego no Brasil colonial. História, Ciências, Saúde - Manguinhos, Rio de Janeiro, v.11, n.1, p.131-140. 2004. 